\title{
Validation of Skeletal Muscle Volume as a Nutritional Assessment in Patients With Gastric or Colorectal Cancer Before Radical Surgery
}

\author{
Takayuki Endo ${ }^{\mathrm{a}, \mathrm{b}}$, Chika Momoki $^{\mathrm{c}}$, Minori Yamaoka ${ }^{\mathrm{b}}$, Saki Hachino ${ }^{\mathrm{b}}$, Satoshi Iwatani ${ }^{\mathrm{b}}$, \\ Seiji Kiyota ${ }^{\mathrm{d}}$, Hiromu Tanaka ${ }^{\mathrm{d}}$, Daiki Habu ${ }^{\mathrm{a}, \mathrm{e}}$
}

\begin{abstract}
Background: Recently, some studies have reported the importance of sarcopenia as a prognostic factor in patients with gastrointestinal cancer who have undergone surgery. We aimed to examine skeletal muscle volume for use in nutritional assessment of preoperative patients, and to compare the results with those of other conventional methods of nutritional assessment, such as biochemical or body composition values.

Methods: This was an open cohort study which examined skeletal muscle volume for use in nutritional assessment of preoperative patients. A total of 121 patients with gastrointestinal cancer who underwent radical surgery were enrolled in this study between June 1, 2008 and December 31, 2012. There were 39 and 82 patients with gastric and colorectal cancer, respectively. The primary outcome of this study was postoperative overall survival. The secondary outcomes were postoperative survival from cancer-related deaths, recurrences of cancer after surgery, postoperative complications, and postoperative hospital inpatient stay (measured in days). Univariate and multivariate analyses were used to identify the relevant factors for postoperative outcomes mentioned above.
\end{abstract}

Results: Skeletal muscle volume was a significant (hazard ratio (HR): $3.34,95 \%$ confidence interval $(\mathrm{CI}): 1.21-9.17, \mathrm{P}=0.020)$ independent prognostic factor for cancer-related deaths in patients with gastric or colorectal cancer who had undergone surgery, and a marginally inde-

Manuscript submitted July 4, 2017, accepted July 20, 2017

aDepartment of Medical Nutrition, Graduate School of Life Science, Osaka City University, 3-3-138 Sugimoto, Sumiyoshi-ku Osaka-shi, Osaka 5588585, Japan

bDietary Section, Department of Surgery, Higashisumiyoshi Morimoto Hospital, 3-2-66 Takaai, Higashisumiyoshi-ku Osaka-shi, Osaka 546-0014, Japan 'Department of Food and Nutrition, Faculty of Contemporary Human Life Science, Tezukayama University, 3-1-3 Gakuenminami, Nara-shi, Nara 6318585, Japan

dDepartment of Surgery, Higashisumiyoshi Morimoto Hospital, 3-2-66 Takaai, Higashisumiyoshi-ku Osaka-shi, Osaka 546-0014, Japan

${ }^{e}$ Corresponding Author: Daiki Habu, Department of Medical Nutrition, Graduate School of Life Science, Osaka City University, 3-3-138 Sugimoto, Sumiyoshi-ku Osaka-shi, Osaka 558-8585, Japan.

Email: habu@life.osaka-cu.ac.jp

doi: https://doi.org/10.14740/jocmr3129w pendent (HR: $2.48,95 \% \mathrm{CI}: 0.91-6.81, \mathrm{P}=0.077$ ) factor that negatively contributed to overall survival in these patients. In contrast, the preoperative skeletal muscle volume was not correlated with the recurrence of cancer, and was not significantly correlated with the occurrence of severe complications after surgery or prolongation of hospitalization.

Conclusions: The preoperative skeletal muscle volume was a significant prognostic factor in patients with gastric or colorectal cancers. Therefore, the estimation of skeletal muscle volume may be important for stable, long-term nutritional assessment in patients with gastrointestinal cancers.

Keywords: Gastric cancer; Colorectal cancer; Preoperative nutritional assessment; Prognostic factor; Sarcopenia; Skeletal muscle volume

\section{Introduction}

Gastric and colorectal cancers occur very commonly in Japan [1]. The standard therapy for these cancers is curative surgery. Pre-operatively, patients with gastric or colorectal cancer often experience malnutrition due to insufficient oral intake, digestive disorders, or malabsorption that occur because these patients often have gastrointestinal tract dysfunction [2]. Furthermore, concomitant with the increase in age of patients in Japan, the number of patients with age-related malnutrition has increased recently. Therefore, the pre-operative nutritional assessment of these patients has become increasingly important to ensure successful treatment.

The Greek word "sarcopenia" translates to "a decrease in skeletal muscle volume". Although decreases in skeletal muscle volume denote primary sarcopenia, secondary sarcopenia can be caused by the weakening of muscle power and muscular dysfunction due to aging, malnutrition, disuse syndrome, or cancerous cachexia [3].

Skeletal muscle is believed to be the largest storehouse of proteins in the body [4]. Thus, the measurement of the systemic skeletal muscle volume is regarded as an important parameter of nutritional assessment of whole body protein; this is independent of the levels of serum albumin.

Lately, some studies have reported the importance of sarcopenia as a prognostic factor in patients with gastrointestinal cancer 
who have undergone surgery [5-8]. However, so far, the validity of sarcopenia as prognostic factor has seemed to be controversial.

In this study, we have prospectively validated the measurement of skeletal muscle volume as a nutritional assessment in patients with gastric or colorectal cancer prior to undergoing radical surgeries. And we aimed to examine skeletal muscle volume for use in nutritional assessment of preoperative patients, and to compare the results with those of other conventional methods of nutritional assessment, such as biochemical or body composition values.

\section{Materials and Methods}

\section{Study design and participants}

This was an open cohort study which examined skeletal muscle volume for use in nutritional assessment of preoperative patients. A total of 165 patients in our hospital were enrolled in this study between June 1, 2008 and December 31, 2012. After they underwent surgeries, 44 patients were excluded because they could not undergo radical surgery, because of either remote metastases or stage IV cancers (Fig. 1). Cancer staging was performed according to the guidelines of the Union for International Cancer Control (UICC) [9].

The primary outcome of this study was postoperative overall survival. The secondary outcomes were postoperative survival from cancer-related deaths, recurrences of cancer after surgery, postoperative complications, and postoperative hospital inpatient stay (measured in days).

All patients provided informed consent prior to participating in this study. The study was conducted in accordance with the Declaration of Helsinki and was approved by the ethics committee of our hospital.

\section{Follow-up and end point}

Follow-up started on the day of surgery for each individual patient and ended at the day of death, censoring, or at the end point of the study, which was December 31, 2014.

\section{Anthropometric measurements}

Body composition was assessed by bioelectrical impedance analysis (BIA) (Inbody S20; Biospace, Seoul, Korea) [10]; the values of total body fat percentage, estimated visceral fat area (VFA), and skeletal muscle mass were used for analysis.

The skeletal mass index (SMI) was calculated from the total appendicular skeletal muscle mass (ASM) and the height, using the following formula: SMI $\left(\mathrm{kg} / \mathrm{m}^{2}\right)=\operatorname{ASM}(\mathrm{kg}) /$ height $\left(\mathrm{m}^{2}\right)$.

\section{Laboratory data and nutritional status assessment}

To evaluate the nutritional status of patients, data were collected for the following parameters: serum hemoglobin $(\mathrm{Hb})$

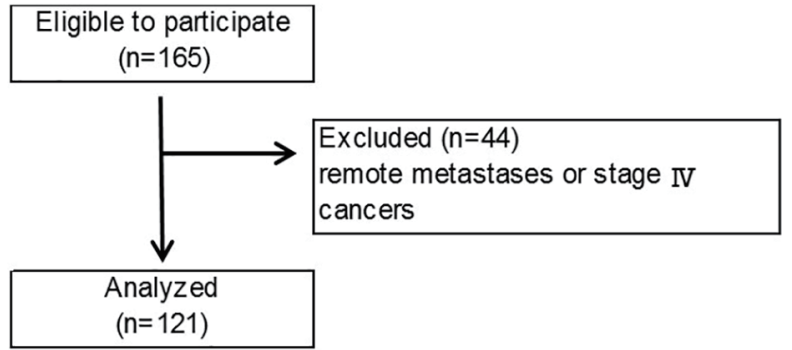

Figure 1. Flow diagram according to selection and exclusion criteria.

concentration, white blood cell (WBC) count, total lymphocyte count (TLC), levels of C-reactive protein (CRP), albumin (Alb), and hemoglobin A1c (HbAlc). To synthetically assess the nutritional status using the plural items, the prognostic nutritional index (PNI) [11] was determined. The PNI was calculated using the following formula: $\mathrm{PNI}=10 \times \mathrm{Alb}+0.005$ $\times$ TLC. The levels of the carcinoembryonic antigen (CEA) and carbohydrate antigen (CA) 19-9 were measured as cancer markers.

\section{Complications}

Complications after surgery were classified according to the Clavien-Dindo classification [12]. In this study, patients with a Clavien-Dindo classification grade of 2 or more were defined to be experiencing significant complications after undergoing surgery.

\section{Comorbidities}

Comorbidities were assessed using the Charlson comorbidity index [13]. Subjects were evaluated by their acuity of disease, with higher scores indicating more severe comorbidities.

\section{Postoperative hospital inpatient stays}

The median inpatient periods after surgery in patients with gastric and colorectal cancers were 19 days (range, 7 - 69) and 15 days (range, 8 - 103), respectively. Therefore, for the purpose of analysis, the inpatient periods after surgery were classified into two categories, based on the median values: $\geq 19$ and $\geq 15$ days or $<19$ and $<15$ days for gastric and colorectal cancer, respectively.

\section{Statistical analysis}

Survival curves were constructed during the follow-up period using the Kaplan-Meier method, and were compared using the log-rank test.

The Cox proportional hazard model was used for univariate and multivariate analyses to identify the relevant factors for postoperative overall survival and postoperative survival from 
cancer-related deaths. Univariate and multivariate logistic regression models were used to identify the relevant factors for the recurrence of cancer, occurrence of severe complications, and inpatient periods after surgery.

Univariate and multivariate Cox proportional hazard models or the logistic regression model were used to obtain crude and adjusted hazard ratios (HRs) or odds ratio (ORs) of the relevant factors for the above-mentioned occurrences after surgery. For analysis, each variable was classified into two categories as follows: age, either $\geq 75$ years or $<75$ years; sex, either male or female; the tumor nodes metastasis (TNM), for analysis, the variables were classified into different categories as follows: stage I, II, or III; primary site, either stomach or colorectal; the Charlson comorbidity index, either $>3$ or $\leq$ 2; histological type, either undifferentiated or differentiated; CEA levels, either $\geq 6 \mathrm{ng} / \mathrm{mL}$ or $<6 \mathrm{ng} / \mathrm{mL}$; CA19-9 levels, either $\geq 37 \mathrm{U} / \mathrm{mL}$ or $<37 \mathrm{U} / \mathrm{mL}$; CRP, either $\geq 0.2 \mathrm{mg} / \mathrm{dL}$ or $<$ $0.2 \mathrm{mg} / \mathrm{dL} ; \mathrm{Alb}<3.5 \mathrm{~g} / \mathrm{dL}$ or $\geq 3.5 \mathrm{~g} / \mathrm{dL}, \mathrm{Hb}$, either $<11 \mathrm{~g} / \mathrm{dL}$ and $<10 \mathrm{~g} / \mathrm{dL}$ or $\geq 11 \mathrm{~g} / \mathrm{dL}$ and $\geq 10 \mathrm{~g} / \mathrm{dL}$ in male and female patients, respectively; HbA1c, either $\geq 6.5 \%$ or $<6.5 \%$; PNI, either $<40$ or $\geq 40$; body mass indices (BMIs), for analysis, the variables were classified into different categories as follows: either $18.5-24.9 \mathrm{~kg} / \mathrm{m}^{2}$, or $<18.5 \mathrm{~kg} / \mathrm{m}^{2}$, or $\geq 25 \mathrm{~kg} / \mathrm{m}^{2}$; VFA, either $\geq 100 \mathrm{~cm}^{2}$ or $<100 \mathrm{~cm}^{2}$; body fat, either $\geq 30 \%$ and $\geq 42 \%$ or $<30 \%$ and $<42 \%$ in male and female patients, respectively; surgical procedure, either laparotomy or laparoscopy; chemotherapy after surgery, either presence or absence. The SMI, either $<6.25$ and $<5.17 \mathrm{~kg} / \mathrm{m}^{2}$ or $\geq 6.25$ and $\geq 5.17$ $\mathrm{kg} / \mathrm{m}^{2}$ in male and female patients, respectively, was classified according to the quartile. Variables were included in the multivariate model, using the results of the univariate HRs or ORs. Variables with strong correlation coefficients were excluded in the same model, because strong correlation may be a cause for multicollinearity.

SPSS ver. 23.0 statistical software for Windows (SPSS Inc., Chicago, IL, USA) was used for analytical comparisons of time-dependent data. SAS 9.4 software (SAS Institute, Inc., Cary, NC, USA) was used for the univariate and multivariate analyses. A P value of $<0.05$ was considered statistically significant.

\section{Results}

\section{Preoperative characteristics of the patients}

The preoperative characteristics of the patients are listed in Table 1 . Of these patients, 81 were men and 40 were women, with an average age of $70.3 \pm 9.4$ years. There were 39 and 82 patients with gastric and colorectal cancer, respectively.

\section{Postoperative overall survival}

The differences in cumulative overall survival rates after surgery, according to the SMI classification are shown in Figure 2 . The SMI group with lower values (SMI values $<6.25 \mathrm{~kg}$ / $\mathrm{m}^{2}$ and $<5.17 \mathrm{~kg} / \mathrm{m}^{2}$ in male and female patients, respectively)
Table 1. Characteristics

\begin{tabular}{|c|c|}
\hline & $n=121$ \\
\hline Age (years) & $70.3 \pm 9.4$ \\
\hline \multicolumn{2}{|l|}{ Sex } \\
\hline Male (n, \%) & $81(66.9)$ \\
\hline \multicolumn{2}{|l|}{ Stage $(\mathrm{n}=118)$} \\
\hline Stage I-II & $74(61.2)$ \\
\hline Stage III & $44(36.4)$ \\
\hline \multicolumn{2}{|l|}{ Disease } \\
\hline Colorectal cancer & $82(67.8)$ \\
\hline Stomach cancer & $39(32.2)$ \\
\hline \multicolumn{2}{|c|}{ Charlson comorbidity index (points) } \\
\hline 2 & $78(64.5)$ \\
\hline 3 & $31(25.6)$ \\
\hline 4 & $10(8.3)$ \\
\hline 5 & $2(1.7)$ \\
\hline $\operatorname{CEA}(\mathrm{ng} / \mathrm{mL})(\mathrm{n}=117)$ & $21.7 \pm 3.8$ \\
\hline CA19-9 (U/mL) $(\mathrm{n}=113)$ & $42.4 \pm 161.8$ \\
\hline $\mathrm{CRP}(\mathrm{mg} / \mathrm{dL})(\mathrm{n}=104)$ & $0.7 \pm 1.5$ \\
\hline Albumin $(\mathrm{g} / \mathrm{dL})(\mathrm{n}=105)$ & $3.6 \pm 0.6$ \\
\hline Hemoglobin (g/dL) (n=107) & $12.0 \pm 2.6$ \\
\hline HbA1c $(\%)(n=92)$ & $6.1 \pm 0.9$ \\
\hline PNI (points) $(\mathrm{n}=100)$ & $45.0 \pm 7.0$ \\
\hline \multicolumn{2}{|l|}{ BMI $\left(\mathrm{kg} / \mathrm{m}^{2}\right)$} \\
\hline Male & $21.7 \pm 3.8$ \\
\hline Female & $21.0 \pm 3.5$ \\
\hline \multicolumn{2}{|l|}{$\operatorname{SMI}\left(\mathrm{kg} / \mathrm{m}^{2}\right)$} \\
\hline Male & $6.8 \pm 1.1$ \\
\hline Female & $5.5 \pm 0.8$ \\
\hline \multicolumn{2}{|l|}{$\operatorname{VFA}\left(\mathrm{cm}^{2}\right)$} \\
\hline Male $(\mathrm{n}=77)$ & $108.2 \pm 62.9$ \\
\hline Female $(\mathrm{n}=39)$ & $115.2 \pm 77.9$ \\
\hline \multicolumn{2}{|l|}{ Body fat (\%) } \\
\hline Male & $22.3 \pm 7.2$ \\
\hline Female & $30.4 \pm 9.0$ \\
\hline
\end{tabular}

Data were expressed as $n(\%)$ or mean \pm SD.

had significantly shorter survival rates than the SMI group with higher values $(\mathrm{P}=0.019)$.

The results of univariate and multivariate Cox proportional hazard analysis for factors contributing to postoperative overall survival are shown in Table 2. Univariate analysis of the factors contributing to postoperative overall survival showed that the following factors were significantly correlated to postoperative overall survival: age 75 years or more (HR: 4.03, 95\% confidence interval (CI): $1.66-9.76)$, CEA $6 \mathrm{ng} /$ $\mathrm{dL}$ or more (HR: $2.84,95 \% \mathrm{CI}: 1.17-6.93), \mathrm{Alb}<3.5 \mathrm{~g} / \mathrm{dL}$ 


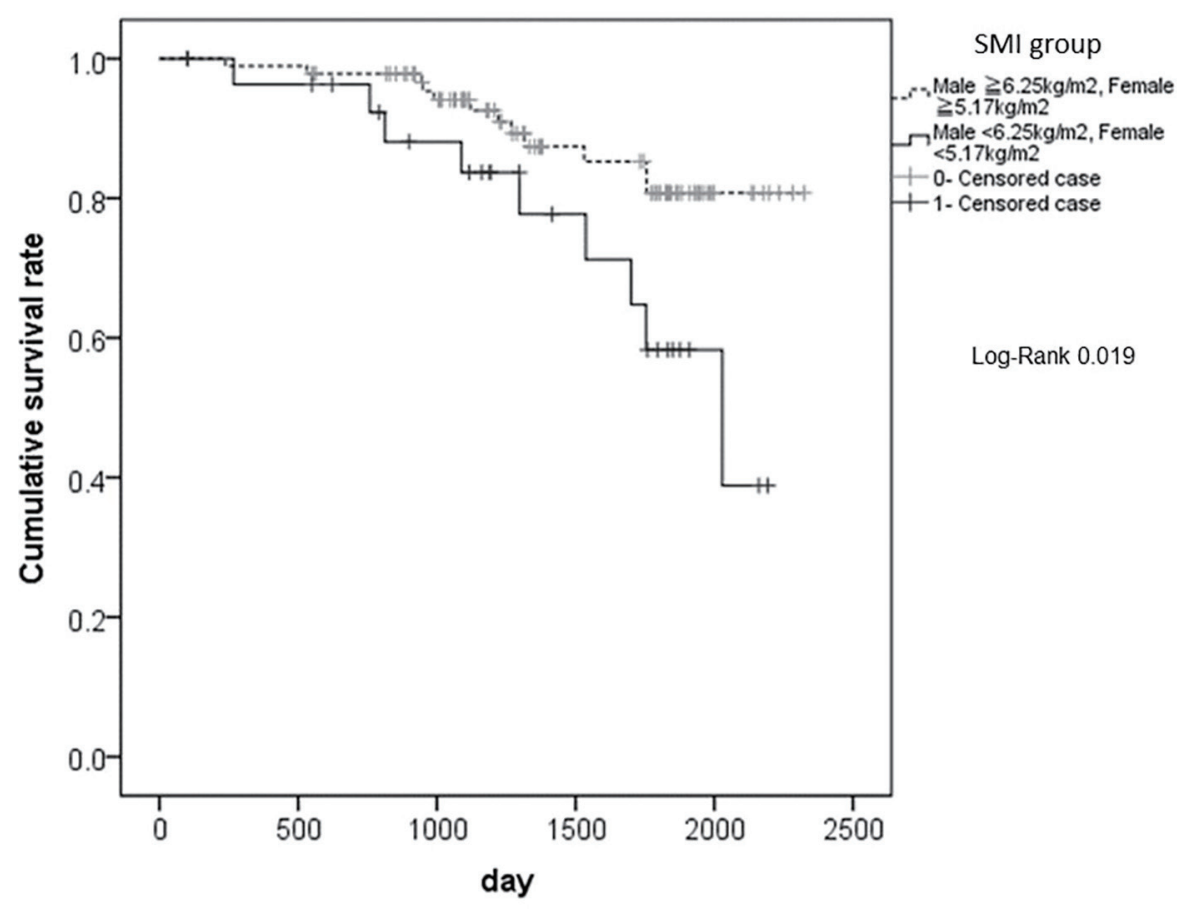

Figure 2. The differences in cumulative overall survival rates after surgery, according to the SMI classification. The SMI group with lower values (SMI values $<6.25 \mathrm{~kg} / \mathrm{m}^{2}$ and $<5.17 \mathrm{~kg} / \mathrm{m}^{2}$ in male and female patients, respectively) had significantly shorter survival rates than the SMI group with higher values $(P=0.019)$. SMI: smooth muscle index.

(HR: 2.94, 95\% CI: $1.16-7.45), \mathrm{Hb}<11 \mathrm{~g} / \mathrm{dL}$ and $<10 \mathrm{~g} / \mathrm{dL}$ in males and females, respectively (HR: $3.41,95 \% \mathrm{CI}: 1.33$ $8.75)$, and $\mathrm{SMI}<6.25 \mathrm{~kg} / \mathrm{m}^{2}$ and $<5.17 \mathrm{~kg} / \mathrm{m}^{2}$ in males and females, respectively (HR: 2.70, 95\% CI: 1.13 - 6.41).

$\mathrm{Hb}$ was not included in the multivariate model because it showed strong correlation with Alb. The multivariate Cox proportional hazard analysis was performed for four factors (age, CEA, Alb, and SMI). In this analysis, the SMI (HR: 2.48, 95\% CI: $0.91-6.81, \mathrm{P}=0.077$ ) had the highest $\mathrm{HR}$, and was a marginally significant factor that negatively contributed to overall survival.

\section{Postoperative survival from cancer-related deaths}

The differences in cumulative survival rates after surgery from cancer-related deaths, according to the SMI classification, are shown in Figure 3. Patients with lower values of SMI had significantly shorter survivals than those with higher values of SMI $(\mathrm{P}=0.013)$.

We conducted univariate and multivariate Cox proportional hazard analysis for factors contributing to postoperative survival from cancer-related deaths (Table 3 ). Three patients were excluded from this analysis because they died due to causes that were not cancer-related. The results of univariate analysis for factors contributing to postoperative survival from cancer-related deaths showed that age (HR: 3.90, 95\% CI: 1.51 - 10.09), Alb (HR: 3.22, 95\% CI: 1.20 - 8.67), Hb (HR: 2.90, 95\% CI: 1.04 - 8.09), and SMI (HR: 3.07, 95\% CI: 1.21 - 7.78) were significantly correlated to postoperative survival from cancer-related deaths. The $\mathrm{Hb}$ was not included in the multivariate analysis because it showed strong correlation with Alb. The multivariate Cox proportional hazard model included the following factors, namely, age, Alb, and SMI. SMI (HR: 3.34, 95\% CI 1.21 - 9.17, $\mathrm{P}=0.020$ ) and Alb (HR: 2.83, 95\% CI: 1.03 - 7.75) were independent factors that contribute to cancer-related deaths.

\section{Postoperative cancer recurrence}

The results of univariate and multivariate logistic regression analyses for factors contributing to the recurrence of cancer within 2 years after surgery are shown in Table 4 . Univariate analysis for factors contributing to the recurrence of cancer showed that the occurrence of stage III cancer (odds ratio (OR): 3.28, 95\% CI: 1.44 - 7.45), and the presence or absence of chemotherapy after surgery (OR: 4.92, 95\% CI: 2.13 - 11.10) were significantly correlated to the recurrence of cancer. The multivariate logistic regression model included the following factors, namely, age, sex, stage, and chemotherapy. Chemotherapy (OR: $3.77,95 \%$ CI: $1.50-9.49$ ) was the only independent factor that contributed to the recurrence of cancer. The SMI did not significantly contribute to the recurrence of cancer.

\section{Complications after surgery}

The results of univariate and multivariate logistic regression analyses for factors contributing to postoperative complications are shown in Table 5. Univariate analysis for factors con- 
Table 2. Univariate and Multivariate Hazard Ratio and 95\% Cl for Association of Postoperative Survival

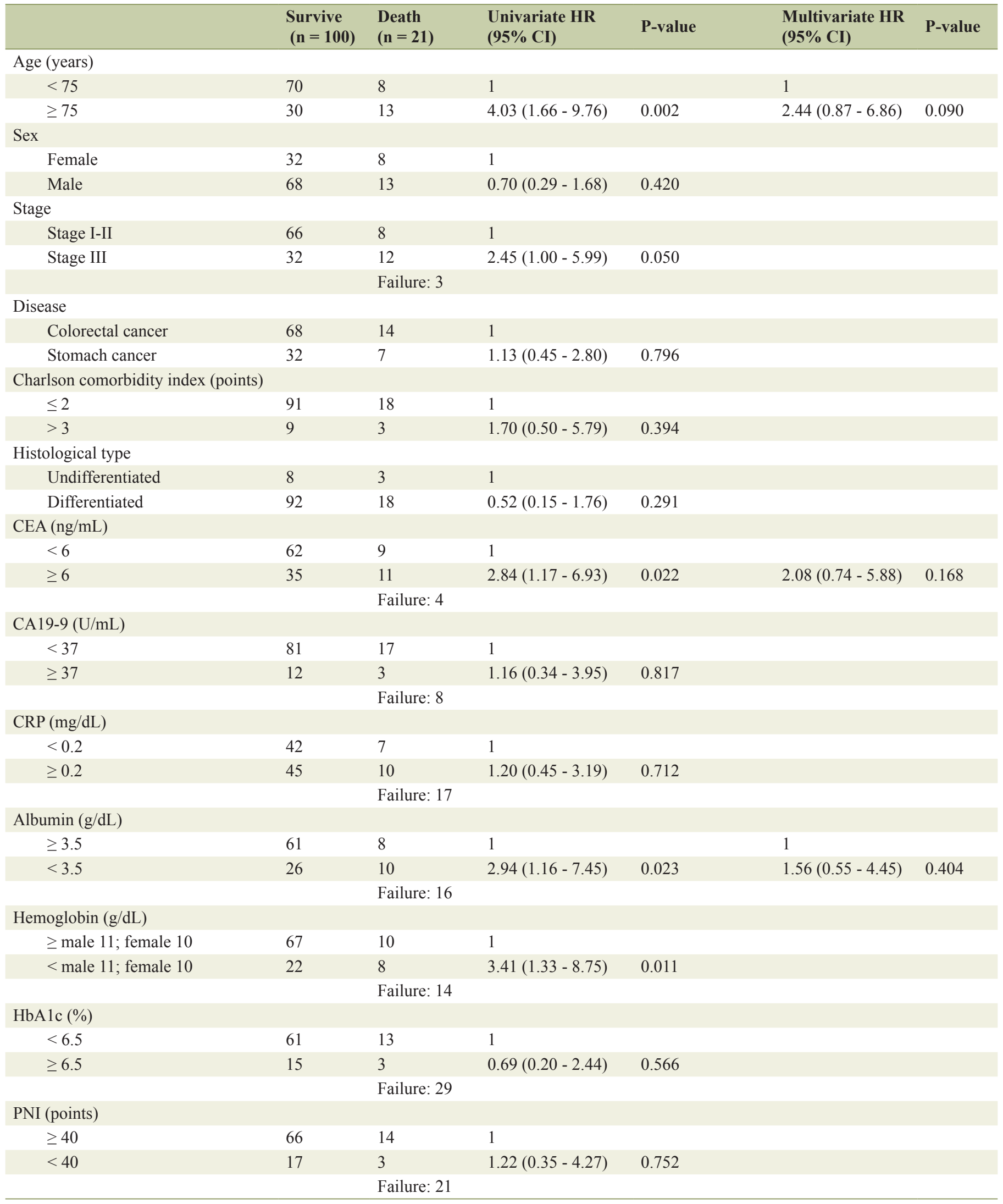


Table 2. Univariate and Multivariate Hazard Ratio and $95 \% \mathrm{Cl}$ for Association of Postoperative Survival - (continued)

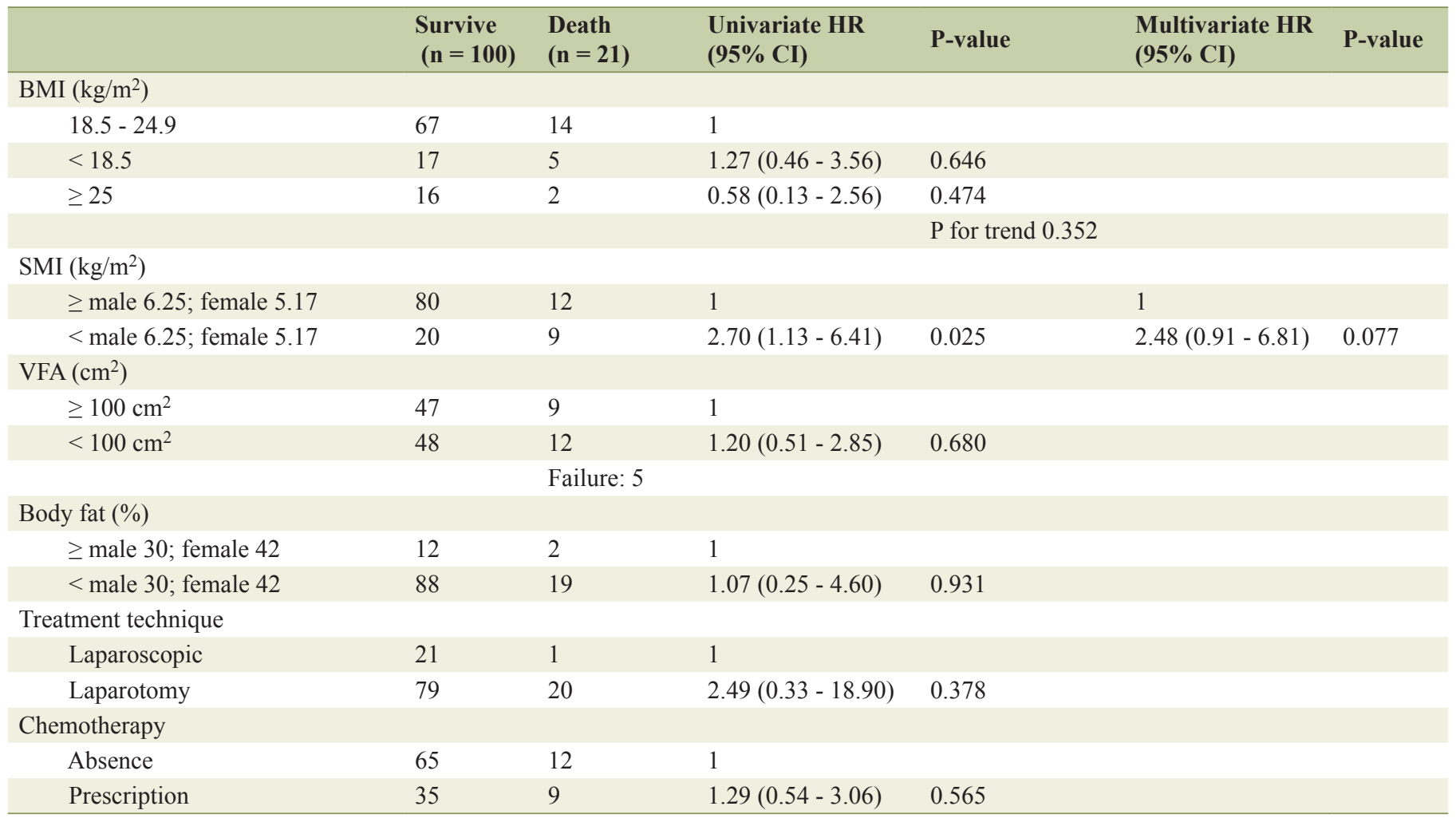

PNI: prognostic nutritional index; CEA: carcinoembryonic antigen; CA19-9: carbohydrate antigen 19-9; CRP: C-reactive protein; VFA: visceral fat area; BMI: body mass index; SMI: skeletal muscle mass index. Multivariate model included age, CEA, albumin and SMI.

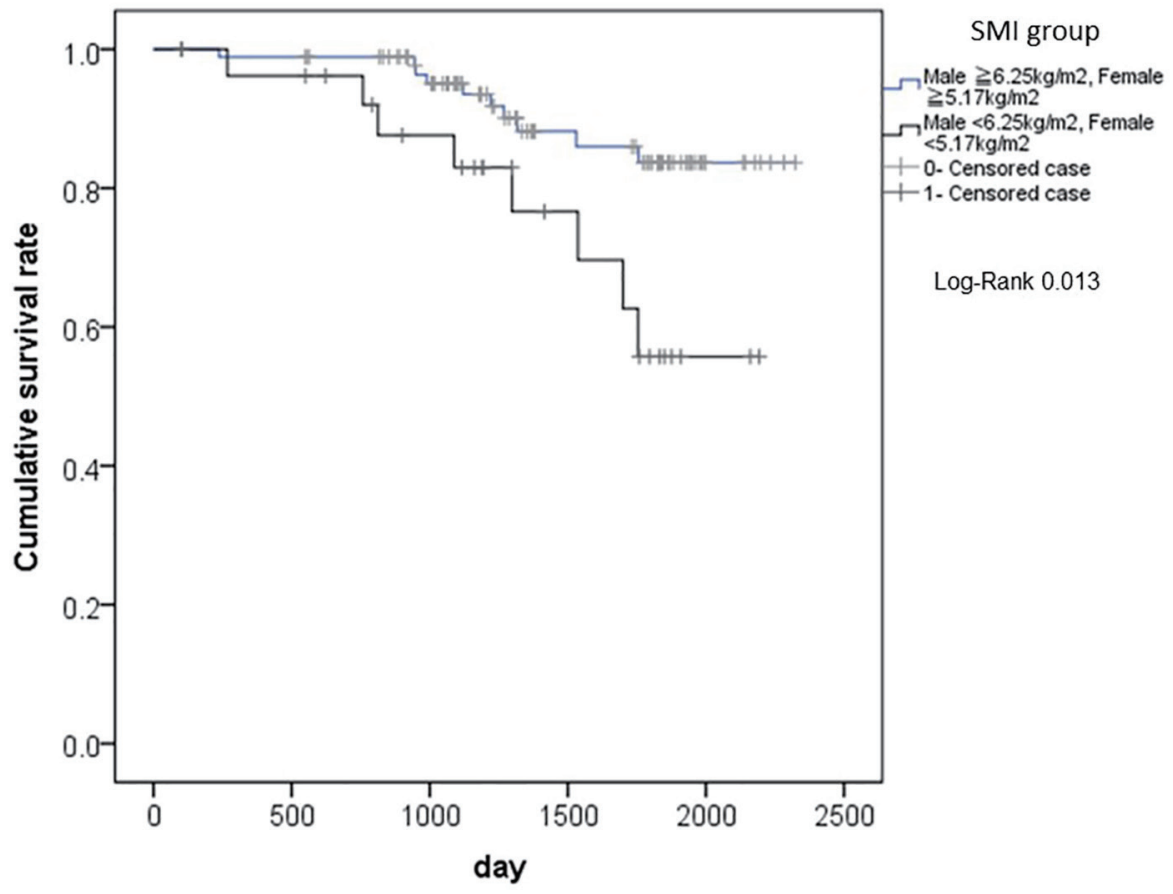

Figure 3. The differences in cumulative survival rates after surgery from cancer-related deaths, according to the SMI classification. Patients with lower values of SMI had significantly shorter survivals than those with higher values of SMI $(P=0.013)$. SMI: smooth muscle index. 
Table 3. Univariate and Multivariate Hazard Ratio and $95 \% \mathrm{Cl}$ for Association of Postoperative Survival (Cancer Death)

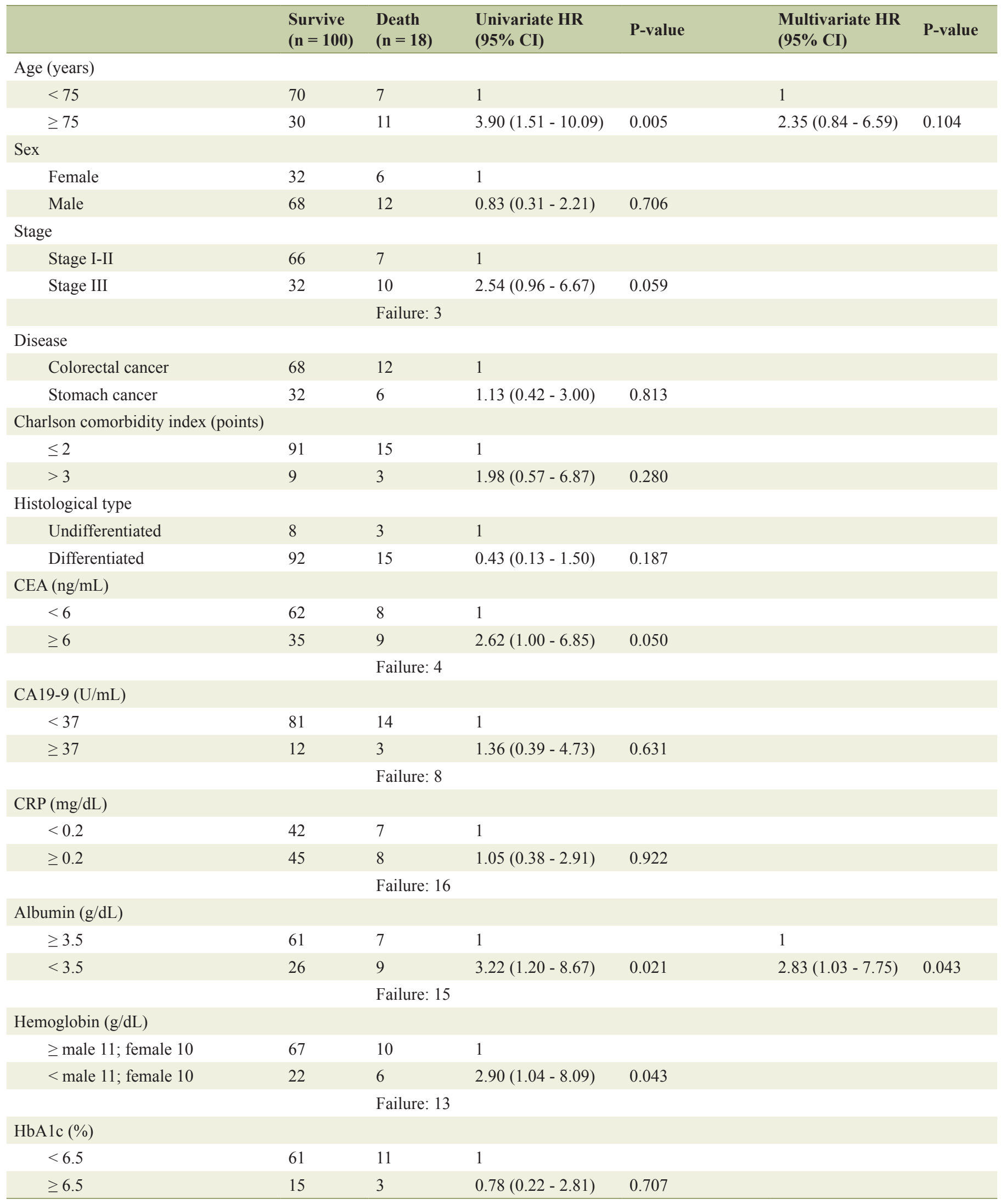


Table 3. Univariate and Multivariate Hazard Ratio and $95 \%$ Cl for Association of Postoperative Survival (Cancer Death)- (continued)

\begin{tabular}{|c|c|c|c|c|c|c|}
\hline & $\begin{array}{l}\text { Survive } \\
(n=100)\end{array}$ & $\begin{array}{l}\text { Death } \\
(n=18)\end{array}$ & $\begin{array}{l}\text { Univariate HR } \\
(95 \% \text { CI) }\end{array}$ & P-value & $\begin{array}{l}\text { Multivariate HR } \\
(95 \% \text { CI })\end{array}$ & P-value \\
\hline & & Failure: 28 & & & & \\
\hline$\geq 40$ & 66 & 12 & 1 & & & \\
\hline$<40$ & 17 & 3 & $1.47(0.41-5.21)$ & 0.555 & & \\
\hline $18.5-24.9$ & 67 & 12 & 1 & & & \\
\hline$<18.5$ & 17 & 4 & $1.33(0.43-4.13)$ & 0.622 & & \\
\hline \multirow{2}{*}{$\geq 25$} & 16 & 2 & $0.65(0.15-2.91)$ & 0.575 & & \\
\hline & & & & $P$ for trend 0.403 & & \\
\hline \multicolumn{7}{|l|}{$\operatorname{VFA}\left(\mathrm{cm}^{2}\right)$} \\
\hline$\geq 100 \mathrm{~cm}^{2}$ & 47 & 8 & 1 & & & \\
\hline \multirow[t]{2}{*}{$<100 \mathrm{~cm}^{2}$} & 48 & 10 & $1.16(0.46-2.95)$ & 0.752 & & \\
\hline & & Failure: 5 & & & & \\
\hline \multicolumn{7}{|l|}{ Body fat (\%) } \\
\hline$\geq$ male $30 ;$ female 42 & 12 & 2 & 1 & & & \\
\hline$<$ male 30 ; female 42 & 88 & 16 & $0.98(0.22-4.24)$ & 0.973 & & \\
\hline \multicolumn{7}{|l|}{ Treatment technique } \\
\hline Laparoscopic & 21 & 0 & & & & \\
\hline
\end{tabular}

PNI: prognostic nutritional index; CEA: carcinoembryonic antigen; CA19-9: carbohydrate antigen 19-9; CRP: C-reactive protein; VFA: visceral fat area; BMI: body mass index; SMI: skeletal muscle mass index. Multivariate model included age, albumin and SMI.

tributing to postoperative complications showed that CA19-9 levels of $37 \mathrm{U} / \mathrm{mL}$ or more (OR: $3.52,95 \% \mathrm{CI}: 1.16-10.74$ ) were significantly correlated with the occurrence of postoperative complications. The following factors were marginally correlated to postoperative complications in patients: being male (OR: 2.36, 95\% CI: 0.92 - 6.02), a Charlson comorbidity index of 2 or more (OR: 2.89, 95\% CI: $0.86-9.71$ ), and the SMI (OR: 2.25, 95\% CI: 0.93 - 5.42).

The multivariate logistic regression analysis was performed for three factors namely, sex, age, and CA19-9 levels. In this analysis, only the CA19-9 levels (OR: 3.95, 95\% CI: 1.24 - 12.64) were a significantly independent factor that contributed to postoperative complications.

\section{Postoperative hospital inpatient days}

The results of univariate and multivariate logistic regression analyses for factors contributing to postoperative hospital inpatient stays (measured in days) are shown in Table 6. Univariate analysis for factors contributing to postoperative hospital inpatient days showed that CRP values of $0.2 \mathrm{mg} / \mathrm{dL}$ or more (OR: 2.52, 95\% CI: 1.14 - 5.59), Alb (OR: 3.27, 95\% CI: 1.34 - 7.97), and undergoing laparotomy (OR: 5.46, 95\% CI: 1.86 - 16.01) were significantly correlated to the number of postoperative hospital inpatient days. The Charlson comorbidity index (OR: 4.73, 95\% CI: 0.99 - 22.60), a PNI value less than 40 (OR: 2.85, 95\% CI: 0.95 - 22.60), and the SMI (OR: 2.22, 95\% CI: 0.92 - 5.39) were marginally correlated to postoperative hospital inpatient days. CRP and PNI were not included in the multivariate model because both these showed strong correlations with Alb. The multivariate logistic regression analysis was performed for six factors, namely, age, sex, Charlson comorbidity index, Alb, SMI, and treatment technique. In this analysis, undergoing laparotomy (OR: 3.72, 95\% CI: 1.07 - 12.90) and Alb (OR: $3.07,95 \%$ CI: 1.18 - 7.95) were 
Table 4. Univariate and Multivariate OR and $95 \% \mathrm{Cl}$ for Association of Postoperative Recurrence

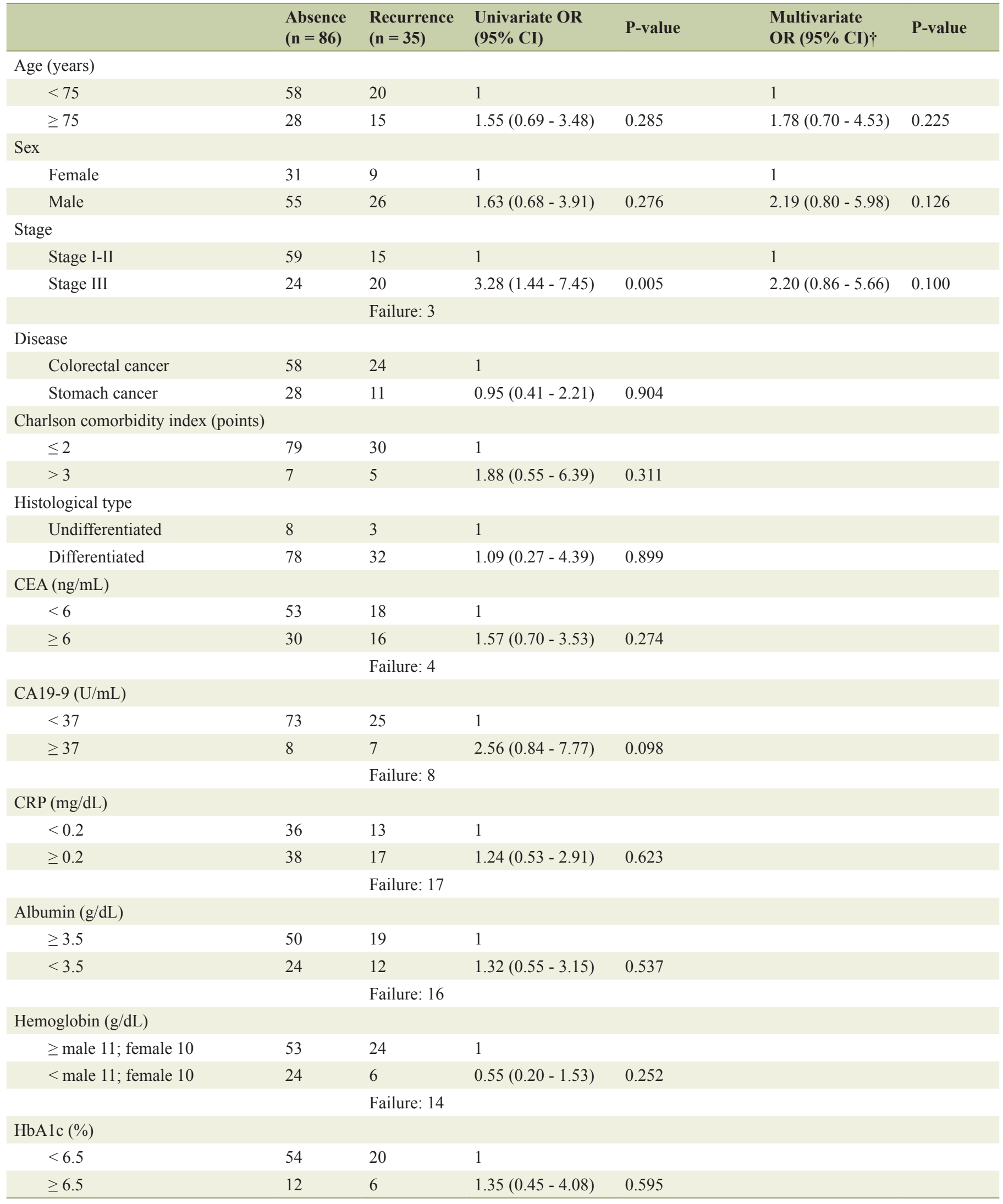


Table 4. Univariate and Multivariate OR and $95 \% \mathrm{Cl}$ for Association of Postoperative Recurrence - (continued)

\begin{tabular}{|c|c|c|c|c|c|c|}
\hline & $\begin{array}{l}\text { Absence } \\
(\mathrm{n}=\mathbf{8 6})\end{array}$ & $\begin{array}{l}\text { Recurrence } \\
(n=35)\end{array}$ & $\begin{array}{l}\text { Univariate OR } \\
(95 \% \text { CI) }\end{array}$ & P-value & $\begin{array}{l}\text { Multivariate } \\
\text { OR }(95 \% \text { CI }) \dagger\end{array}$ & P-value \\
\hline & & Failure: 29 & & & & \\
\hline$\geq 40$ & 55 & 25 & 1 & & & \\
\hline$<40$ & 15 & 5 & $0.73(0.24-2.24)$ & 0.586 & & \\
\hline $18.5-24.9$ & 56 & 25 & 1 & & & \\
\hline$<18.5$ & 17 & 5 & $0.66(0.22-1.99)$ & 0.459 & & \\
\hline \multirow[t]{2}{*}{$\geq 25$} & 13 & 5 & $0.86(0.28-2.68)$ & 0.797 & & \\
\hline & & & & $P$ for trend 0.686 & & \\
\hline \multicolumn{7}{|l|}{$\operatorname{VFA}\left(\mathrm{cm}^{2}\right)$} \\
\hline$\geq 100 \mathrm{~cm}^{2}$ & 38 & 18 & 1 & & & \\
\hline \multirow[t]{2}{*}{$<100 \mathrm{~cm}^{2}$} & 44 & 16 & $0.77(0.35-1.71)$ & 0.518 & & \\
\hline & & Failure: 5 & & & & \\
\hline \multicolumn{7}{|l|}{ Body fat (\%) } \\
\hline$\geq$ male 30 ; female 42 & 11 & 3 & 1 & & & \\
\hline$<$ male $30 ;$ female 42 & 75 & 32 & $1.56(0.41-5.98)$ & 0.514 & & \\
\hline \multicolumn{7}{|l|}{ Treatment technique } \\
\hline Laparoscopic & 19 & 3 & 1 & & & \\
\hline \multicolumn{7}{|l|}{ Chemotherapy } \\
\hline
\end{tabular}

PNI: prognostic nutritional index; CEA: carcinoembryonic antigen; CA19-9: carbohydrate antigen 19-9; CRP: C-reactive protein; VFA: visceral fat area; BMI: body mass index; SMI: skeletal muscle mass index. †Model included age, sex, stage and chemotherapy.

significantly independent factors that negatively contributed to postoperative hospital inpatient days.

\section{Discussion}

In this study, the SMI was a significant independent prognostic factor for cancer-related deaths in patients with gastric or colorectal cancer who had undergone surgery, and a marginally independent factor that negatively contributed to overall survival in these patients. In contrast, the SMI was not correlated to the recurrence of cancer. These findings may suggest why the SMI can predict the prognoses of patients with gastric or colorectal cancer after radical surgeries.

The SMI may not directly affect the increase of tumors or metastasis because it was not correlated to the recurrence of cancer. Lower SMI values that indicate the decrease of skeletal muscle volume in the body of patients may affect the recover- ies from the invasion of surgery, the activities of daily living (ADLs) after discharge, or the conditions of the patients with advanced stages of cancer, and eventually lead to shorter survival after surgery.

First, approximately $60 \%$ of all protein in the body resides in the skeletal muscles. When a patient undergoes severe stresses from invasive cancer surgery, the degeneration of skeletal muscles is increased as a biological reaction against severe damage [14]. The resulting amino acids from the degenerated muscle proteins are utilized as energy sources, raw materials for acute-phase proteins to repair the wounded area, or enhancers of the immune system [15].

In patients with sarcopenia, the decreases in the volumes of skeletal muscles, which are the biggest storehouse of protein, can worsen the protein deficiency after surgery. This lack of adequate levels of muscle proteins may adversely affect the pathological conditions of patients with gastrointestinal cancers after they undergo invasive surgeries. 
Table 5. Univariate and Multivariate OR and $95 \% \mathrm{Cl}$ for Association of Postoperative Complications

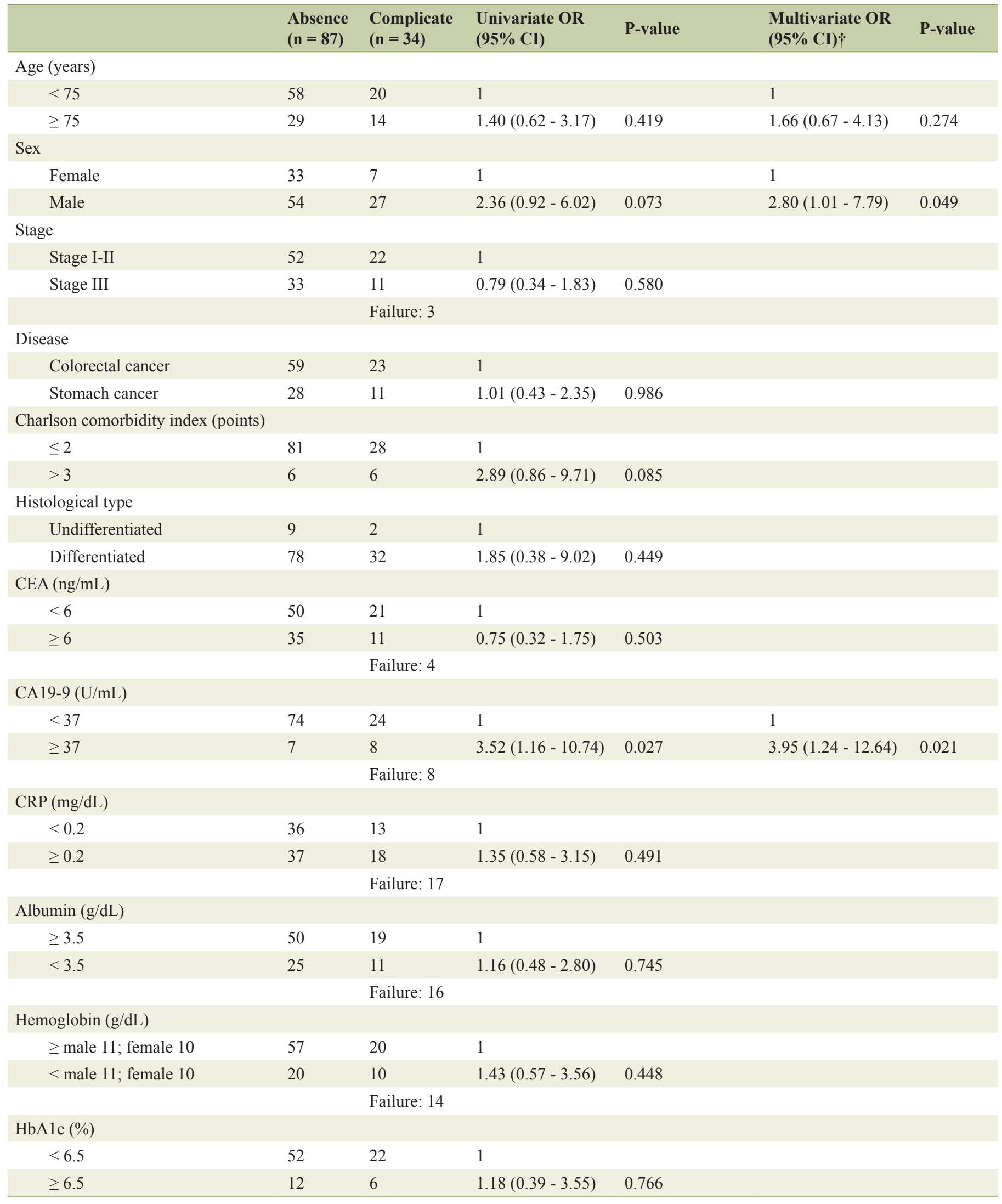


Table 5. Univariate and Multivariate OR and $95 \% \mathrm{Cl}$ for Association of Postoperative Complications - (continued)

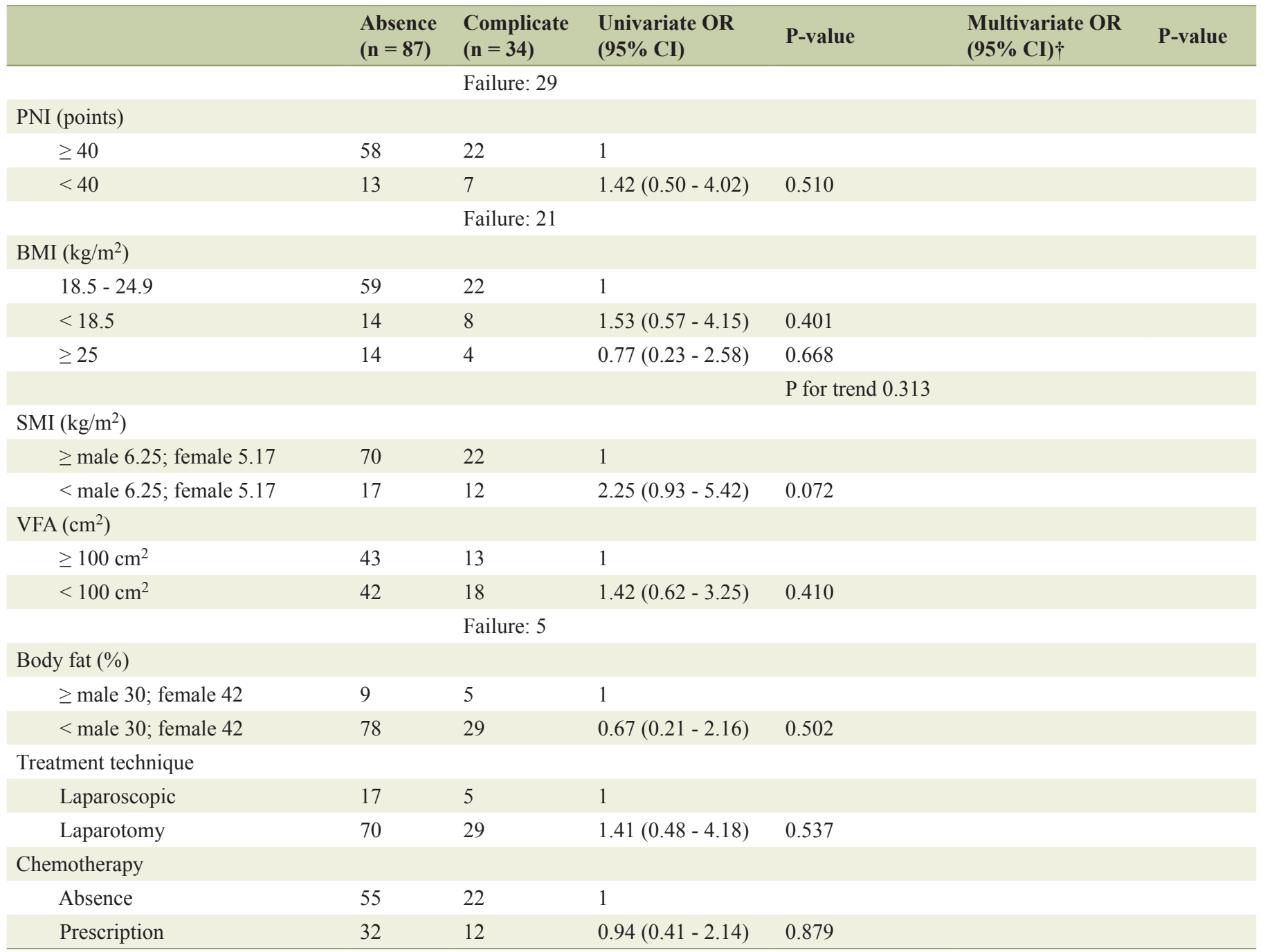

PNI: prognostic nutritional index; CEA: carcinoembryonic antigen; CA19-9: carbohydrate antigen 19-9; CRP: C-reactive protein; VFA: visceral fat area; BMI: body mass index; SMI: skeletal muscle mass index. †Model included age, sex and CA19-9.

Second, patients with sarcopenia have decreased ADLs, increased risks of falling, fracture, requiring nursing care, or of death [16]. If a patient with sarcopenia undergoes severe invasive surgery, the decreases in skeletal muscle volumes may be worsened, and this deteriorated sarcopenic state can cause further decreases in ADLs and exacerbate the pathological conditions.

Third, sarcopenia can be worsened by the presence of malnutrition, disuse atrophy, and cancerous cachexia [4]. In cancerous cachexia, the tumor cells release proinflammatory cytokines such as tumor necrosis factor (TNF)- $\alpha$, interleukin (IL)-1, IL-6, and angiotensin II; these cytokines can cause decreases in skeletal muscle volume. These cytokines may also cause the longterm inhibition of feeding by either stimulating the expression and release of leptin, or mimicking the hypothalamic effect of the excessive negative feedback signaling from leptin, or both, which can prevent the occurrence of the normal compensatory mechanisms for decreased food intake and body weight [16].
Finally, these cytokines (TNF- $\alpha$, IL-1) may inhibit the stimulation of appetite via neuropeptide Y (NPY) or the agouti-related peptide (AGRP) in the hypothalamus; thus, the decreases in appetite and protein malnutrition seen in these patients can deteriorate further [17]. Patients with sarcopenia who have decreased protein reserves may be more severely affected by the release of cytokines from tumor cells that worsen the protein nutritional status. Therefore, preoperative sarcopenia may adversely affect the pathological conditions of patients with cancerous cachexia, and contribute to shortening their life expectancies.

Preoperative sarcopenia may cause the occurrence of complications after surgeries, and may prolong the number of days of hospitalization in some measure through the abovementioned mechanism.

Skeletal muscle volume, which is an analytical factor for body composition, is believed to be a more stable nutritional assessment, compared with biochemical data, such as, serum 
Table 6. Univariate and Multivariate $\mathrm{OR}$ and $95 \% \mathrm{Cl}$ for Association of Length of Stay

\begin{tabular}{|c|c|c|c|c|c|c|}
\hline & $\begin{array}{l}\text { Short term } \\
(n=55)\end{array}$ & $\begin{array}{l}\text { Long term } \\
(\mathrm{n}=66)\end{array}$ & $\begin{array}{l}\text { Univariate OR } \\
(95 \% \mathrm{CI})\end{array}$ & P-value & $\begin{array}{l}\text { Multivariate OR } \\
(95 \% \text { CI }) \dagger\end{array}$ & P-value \\
\hline \multicolumn{7}{|l|}{ Age (years) } \\
\hline$<75$ & 39 & 39 & 1 & & 1 & \\
\hline$\geq 75$ & 16 & 27 & $1.69(0.79-3.61)$ & 0.178 & $1.15(0.45-2.96)$ & 0.772 \\
\hline \multicolumn{7}{|l|}{ Sex } \\
\hline \multicolumn{7}{|l|}{ Stage } \\
\hline Stage I-II & 34 & 40 & 1 & & & \\
\hline \multirow[t]{2}{*}{ Stage III } & 20 & 24 & $1.02(0.48-2.16)$ & 0.959 & & \\
\hline & & Failure: 3 & & & & \\
\hline
\end{tabular}

Disease

$\begin{array}{lllll}\text { Colorectal cancer } & 36 & 46 & 1 & \\ \text { Stomach cancer } & 19 & 20 & 0.82(0.38-1.77) & 0.619\end{array}$

Charlson comorbidity index (points)

$\begin{array}{lllllll}\leq 2 & 53 & 56 & 1 & & 1 & \\ >3 & 2 & 10 & 4.73(0.99-22.60) & 0.051 & 5.73(0.66-49.91) & 0.114\end{array}$

Histological type

$\begin{array}{lllll}\text { Undifferentiated } & 5 & 6 & 1 \\ \text { Differentiated } & 50 & 60 & 1.00(0.29-3.47) & 1.000\end{array}$

CEA (ng/mL)

$\begin{array}{lllll}<6 & 32 & 39 & 1 \\ \geq 6 & 22 & 24 & 0.90(0.43-1.88) & 0.770\end{array}$

CA19-9 (U/mL)

$\begin{array}{lllll}<37 & 47 & 51 & 1 \\ \geq 37 & 4 & 11 & 2.53(0.76-8.51) & 0.132\end{array}$

$\mathrm{CRP}(\mathrm{mg} / \mathrm{dL})$

$\begin{array}{lllll}<0.2 & 27 & 22 & 1 \\ \geq 0.2 & 18 & 37 & 2.52(1.14-5.59) & 0.023\end{array}$

Albumin (g/dL)

$\begin{array}{lllll}\geq 3.5 & 36 & 33 & 1 & \\ <3.5 & 9 & 27 & 3.27(1.34-7.97) & 0.009 \\ & & \text { Failure: } 16 & & \\ \text { moglobin }(\mathrm{g} / \mathrm{dL}) & & & & \\ \geq \text { male } 11 ; \text { female } 10 & 35 & 42 & 1 & 0.610 \\ <\text { male 11; female } 10 & 12 & 18 & 1.25(0.53-2.95) & \end{array}$

HbA1c $(\%)$

$\begin{array}{lllll}<6.5 & 34 & 40 & 1 & \\ \geq 6.5 & 8 & 10 & 1.06(0.38-2.99) & 0.909\end{array}$


Table 6. Univariate and Multivariate OR and $95 \% \mathrm{Cl}$ for Association of Length of Stay - (continued)

\begin{tabular}{|c|c|c|c|c|c|c|}
\hline & $\begin{array}{l}\text { Short term } \\
(n=55)\end{array}$ & $\begin{array}{l}\text { Long term } \\
(n=66)\end{array}$ & $\begin{array}{l}\text { Univariate OR } \\
(95 \% \mathrm{CI})\end{array}$ & P-value & $\begin{array}{l}\text { Multivariate OR } \\
(95 \% \text { CI }) \dagger\end{array}$ & P-value \\
\hline & & Failure: 29 & & & & \\
\hline$\geq 40$ & 39 & 41 & 1 & & & \\
\hline$<40$ & 5 & 15 & $2.85(0.95-8.60)$ & 0.062 & & \\
\hline $18.5-24.9$ & 41 & 40 & 1 & & & \\
\hline$<18.5$ & 7 & 15 & $2.20(0.81-5.95)$ & 0.122 & & \\
\hline \multirow[t]{2}{*}{$\geq 25$} & 7 & 11 & $1.61(0.57-4.57)$ & 0.370 & & \\
\hline & & & & $\mathrm{P}$ for trend 0.564 & & \\
\hline \multicolumn{7}{|l|}{$\operatorname{VFA}\left(\mathrm{cm}^{2}\right)$} \\
\hline$\geq 100 \mathrm{~cm}^{2}$ & 24 & 32 & 1 & & & \\
\hline \multirow[t]{2}{*}{$<100 \mathrm{~cm}^{2}$} & 31 & 29 & $0.70(0.34-1.46)$ & 0.343 & & \\
\hline & & Failure: 5 & & & & \\
\hline \multicolumn{7}{|l|}{ Body fat $(\%)$} \\
\hline$\geq$ male $30 ;$ female 42 & 4 & 10 & 1 & & & \\
\hline$<$ male $30 ;$ female 42 & 51 & 56 & $0.44(0.13-1.49)$ & 0.186 & & \\
\hline \multicolumn{7}{|l|}{ Treatment technique } \\
\hline Laparoscopic & 17 & 5 & 1 & & 1 & \\
\hline
\end{tabular}

PNI: prognostic nutritional index; CEA: carcinoembryonic antigen; CA19-9: carbohydrate antigen 19-9; CRP: C-reactive protein; VFA: visceral fat area; BMI: body mass index; SMI: skeletal muscle mass index. †Model included age, sex, Charlson comorbidity index, albumin, SMI and treatment technique.

albumin concentration or the total number of lymphocytes in serum. In this study, compared with other factors such as body weight or BMI, the skeletal muscle volume was a more useful predictor for survival in patients with gastric or colorectal cancers who had undergone surgeries. Thus, using the BIA method to analyze the body compositions of patients with gastrointestinal cancer before surgery is believed to be useful.

Recently, two relevant studies have been published on gastric cancer. First, Wang et al [18] have shown that sarcopenia is an independent predictor of postoperative complications in patients with gastric cancer after gastrectomy. However, based on our findings, the preoperative skeletal muscle volume does not significantly correlate with the occurrence of severe complications after surgery or prolonged hospitalization. We think the preoperative skeletal muscle volume might function well as a long-term predictor rather than a short-term one. Second, Zhuang et al [19] have asserted in their retrospective study that sarcopenia is an independent predictive factor for severe postoperative complications after radical gastrectomy for gastric cancer and is independently associated with the overall and disease-free survival in patients with TNM stage II and III, but not in patients with TNM stage I disease. However, our findings indicate that the decrease in skeletal muscle volume does not correlate with the recurrence of cancer but may affect the recovery from invasive surgeries, ADLs after discharge, or the conditions of patients with advanced stages of cancer, eventually leading to a shorter survival after surgery. These differences might be validated through large-scale prospective studies in the future.

These findings suggest that it may be important to maintain skeletal muscle volume during the perioperative periods of patients with gastrointestinal cancer, by nutritional support. For this purpose, first, appropriate nutritional therapy should be given to the patients before surgery. The maintenance of skeletal muscle volume in the perioperative period may be ef- 
fective for the enhanced recovery after surgery (ERAS) [20]. Second, after discharge, sufficient nutrition with a protein-rich diet, aerobic exercise such as walking or jogging, and adequate resistance training may be effective in maintaining the skeletal muscle volume. Using these strategies, the maintenance of the skeletal muscle volume during the perioperative periods may be useful to the prolongation of patient survival with gastric or colorectal cancer after radical surgeries.

In future, it is necessary to validate whether the survival of patients with gastrointestinal cancer can be improved by maintaining their skeletal muscle volumes during the perioperative periods, using a prospective intervention study with a greater number of patients.

Our study has some limitations. First, this was a prospective study with a relatively small sample size, and the power of detection was insufficient, particularly in the multivariate Cox proportional hazard model. Second, we did not validate the following muscle functions, namely, hand grip power, and walking speeds; both of these are important factors for the diagnosis of sarcopenia [3]. The importance of these muscle functions as nutritional assessment for patients with gastric or colorectal cancer must be estimated in a future study.

\section{Conclusions}

The preoperative skeletal muscle volume was a significant prognostic factor in patients with gastric or colorectal cancers. Therefore, the estimation of skeletal muscle volume may be important for stable, long-term nutritional assessment in patients with gastrointestinal cancers.

\section{Acknowledgments}

We are grateful to the individuals and the hospital staff who participated in this study.

\section{Conflicts of Interest}

The authors declare that there are no conflicts of interest regarding the publication of this paper.

\section{Author Contributions}

Study conception and design: Takayuki Endo, Chika Momoki, and Daiki Habu. Acquisition: Seiji Kiyota and Hiromu Tanaka. Acquisition, analysis and interpretation of data: Minori Yamaoka, Saki Hachino, and Satoshi Iwatani. Critical revision: Takayuki Endo, Chika Momoki, and Daiki Habu.

\section{References}

1. Foundation for Promotion of Cancer Research. Cancer Statistics in Japan 2015, from http:/ganjoho.jp/data/reg_ stat/statistics/brochure/2015/cancer statistics 2015.

2. Mohri Y, Inoue Y, Tanaka K, Hiro J, Uchida K, Kusunoki M. Prognostic nutritional index predicts postoperative outcome in colorectal cancer. World J Surg. 2013;37(11):2688-2692.

3. Cruz-Jentoft AJ, Baeyens JP, Bauer JM, Boirie Y, Cederholm T, Landi F, Martin FC, et al. Sarcopenia: European consensus on definition and diagnosis: Report of the European Working Group on Sarcopenia in Older People. Age Ageing. 2010;39(4):412-423.

4. Gallagher D, Steven BH, Wang ZM. Skeletal muscle markers in protein and amino acids. Washington, D.C., National Academy Press. 1999:255-277.

5. Huang DD, Zhou CJ, Wang SL, Mao ST, Zhou XY, Lou $\mathrm{N}$, Zhang Z, et al. Impact of different sarcopenia stages on the postoperative outcomes after radical gastrectomy for gastric cancer. Surgery. 2017;161(3):680-693.

6. Grotenhuis BA, Shapiro J, van Adrichem S, de Vries M, Koek M, Wijnhoven BP, van Lanschot JJ. Sarcopenia/ Muscle Mass is not a Prognostic Factor for Short- and Long-Term Outcome After Esophagectomy for Cancer. World J Surg. 2016;40(11):2698-2704.

7. Fukuda Y, Yamamoto K, Hirao M, Nishikawa K, Nagatsuma Y, Nakayama T, Tanikawa S, et al. Sarcopenia is associated with severe postoperative complications in elderly gastric cancer patients undergoing gastrectomy. Gastric Cancer. 2016;19(3):986-993.

8. Lieffers JR, Bathe OF, Fassbender K, Winget M, Baracos VE. Sarcopenia is associated with postoperative infection and delayed recovery from colorectal cancer resection surgery. Br J Cancer. 2012;107(6):931-936.

9. Unio internationalis contra cancrum. TNM classification of malignant tumors, 7th edition (Wiley-Blackwell).

10. Lukaski HC, Johnson PE, Bolonchuk WW, Lykken GI. Assessment of fat-free mass using bioelectrical impedance measurements of the human body. Am J Clin Nutr. 1985;41(4):810-817.

11. Broggi MS, Patil D, Baum Y, Nieh PT, Alemozaffar M, Pattaras JG, Ogan K, et al. Onodera's prognostic nutritional index as an independent prognostic factor in clear cell renal cell carcinoma. Urology. 2016;96:99-105.

12. Dindo D, Demartines N, Clavien PA. Classification of surgical complications: a new proposal with evaluation in a cohort of 6336 patients and results of a survey. Ann Surg. 2004;240(2):205-213.

13. Charlson ME, Pompei P, Ales KL, MacKenzie CR. A new method of classifying prognostic comorbidity in longitudinal studies: development and validation. J Chronic Dis. 1987;40(5):373-383.

14. Demling RH. Nutrition, anabolism, and the wound healing process: an overview. Eplasty. 2009;9:e9.

15. Blackburn GL, Maini BS, Pierce EC, Jr. Nutrition in the critically ill patient. Anesthesiology. 1977;47(2):181-194.

16. Amitani M, Asakawa A, Amitani H, Inui A. Control of food intake and muscle wasting in cachexia. Int $\mathrm{J}$ Biochem Cell Biol. 2013;45(10):2179-2185.

17. Inui A. Cancer anorexia-cachexia syndrome: current issues in research and management. CA Cancer J Clin. 2002;52(2):72-91. 
18. Wang SL, Zhuang CL, Huang DD, Pang WY, Lou N, Chen FF, Zhou CJ, et al. Sarcopenia adversely impacts postoperative clinical outcomes following gastrectomy in patients with gastric cancer: a prospective study. Ann Surg Oncol. 2016;23(2):556-564.

19. Zhuang CL, Huang DD, Pang WY, Zhou CJ, Wang SL, Lou N, Ma LL, et al. Sarcopenia is an independent predictor of severe postoperative complications and long- term survival after radical gastrectomy for gastric cancer: analysis from a large-scale cohort. Medicine (Baltimore). 2016;95(13):e3164.

20. Fearon KC, Ljungqvist O, Von Meyenfeldt M, Revhaug A, Dejong CH, Lassen K, Nygren J, et al. Enhanced recovery after surgery: a consensus review of clinical care for patients undergoing colonic resection. Clin Nutr. 2005;24(3):466-477. 